\title{
THE ISSUE OF CONTACT STRENGTH OCCURING IN POLYETHYLENE FLAT INSERTS OF TOTAL KNEE ENDOPROSTHESES
}

\author{
Marcin Nabrdalik \\ Institute of Mechanical Technology, Czestochowa University of Technology \\ Czestochowa, Poland \\ marcin@iop.pcz.pl
}

\begin{abstract}
The paper presents the numerical analysis of stress and strain occurring in the most wearable parts of knee joint endoprostheses. In the knee joint that would be the pair: sled - flat insert. The complexity of the processes taking place both in natural and artificial joints makes it necessary to conduct the analysis on the 3D model and base it on already existing mathematical models. Finite elements method makes it possible to calculate the stress in particular elements of the tested model. The interaction between the two parts of endoprosthesis takes place on a comparatively small contact surface. The material on that surface is under a spatial state of stress and its stress distribution is very complex and can be designated only as resilience theory. High stress caused by pressure between the two parts is called contact stress.
\end{abstract}

Keywords: endoprosthesis of knee joint, stress, strain, Hertz theory

The major idea of knee endoprosthesis alloplastics is to decrease the wear-off level of material in the contact area between the femoral metal and tibial polyethylene elements. With high pressure values the friction conditions between the two parts get worse which causes a lot of wear-off left-overs and may lead to implanting failure.

\section{The issue of designing the contact stress according to the Hertz theory}

Where two objects are pressed to each other with some strength, there may be observed some stress called contact stress.

In the case of sled and flat insert contact area it is assumed that the initial point of contact between the elements has a common normal " $\mathrm{z}$ " and orthogonal to it common contact facet. In the mentioned curvature point of elements in contact, there can be main curvature radiuses ( $\min$ and max) $r_{1}$ and $r_{1}^{\prime}$ - the element surface 1 for the sled made of CoCrMo, and $r_{2}$ and $r_{2}^{\prime}$ - the element surface 2 for the insert made of polyethylene. The modules of longitudinal resilience and Poisson's coefficients 
of the 1 and 2 elements, are assigned respectively $E_{1}, v_{1}$ for a sled made of the alloy CoCrMo, and $\mathrm{E}_{2} v_{2}$ for the polyethylene insert. Let us assume that elements 1 and 2 are pressed by forces $\mathrm{P}$ along the normal " $\mathrm{z}$ ". As a result of that pressing the elements are partially deformed and the common contact area - according to Hertz's theory - is finite by the elipse with semi-axes - bigger " $a$ " and smaller " $b$ ", described in the pattern $[6,7]$ :

$$
a=\alpha \sqrt[3]{\frac{P m}{n}} ; \quad b=\beta \sqrt[3]{\frac{P m}{n}}
$$

where:

$$
\begin{gathered}
n=\frac{8}{3} \frac{E_{1} E_{2}}{E_{2}\left(1-v_{1}^{2}\right)+E_{1}\left(1-v_{2}^{2}\right)} \\
m=\frac{4}{\frac{1}{r_{1}}+\frac{1}{r_{1}^{\prime}}+\frac{1}{r_{2}}+\frac{1}{r_{2}^{\prime}}}
\end{gathered}
$$

$\alpha, \beta$ - coefficient depending on the value of the ratio $\frac{B^{*}}{A^{*}}$, with $A^{*}=2 / m$

$$
B^{*}=\frac{1}{2} \sqrt{\left(\frac{1}{r_{1}}-\frac{1}{r_{1}^{\prime}}\right)^{2}+\left(\frac{1}{r_{2}}-\frac{1}{r_{2}^{\prime}}\right)^{2}+2\left(\frac{1}{r_{1}}-\frac{1}{r_{1}^{\prime}}\right)\left(\frac{1}{r_{2}}-\frac{1}{r_{2}^{\prime}}\right) \cos 2 \varphi}
$$

$\varphi$ - the angle between corresponding facets of the major curvatures of elements in contact.

The markers:

$P$ - force affecting the sled [N],

$E_{1}$ - module of the metal sled resilience [MPa], $\left[\mathrm{N} / \mathrm{mm}^{2}\right]$

$E_{2}$ - module of polyethylene insert resilience [MPa], $\left[\mathrm{N} / \mathrm{mm}^{2}\right]$

$v_{1}$ - the Poisson's coefficient for the alloy CoCrMo

$v_{2}$ - the Poisson's coefficient for the polyethylene UHMWPE

$r_{1}$ - the main radius of the sled's min curvature

$r_{2}$ - the main radius of the sled's max curvature

$r_{2}=r_{2}^{\prime}=\infty$ for the flat insert

The accepted values for the pair CoCrMo - UHMWPE:

$E_{1}=2,1 * 10^{5} \mathrm{MPa}$,

$v_{1}=0,3$

$E_{2}=1000 \mathrm{MPa}$,

$v_{2}=0,4$ 
Considering the max substituted stress $\sigma_{\text {red }}$, the strength condition for calculation is presented as follows:

$$
\sigma_{\text {red }} \cong 0,6 * p_{\max } \leq \sigma_{\text {dop }}
$$

where $\sigma_{d o p}$ - acceptable stress.

To calculate max stress according to Hertz and using patterns for particular cases of contact stresses, the following patterns and rules have been accepted:

1. contact stress: sled - polyethylene flat insert

$$
\begin{gathered}
r_{1}=r_{1}^{\prime}=\frac{d_{2}}{2} \\
r_{2}=r_{2}^{\prime}=\infty \\
A^{*}=\frac{1}{r_{1}} \\
B^{*}=0 \\
k=\frac{1-v_{1}^{2}}{E_{1}}+\frac{1-v_{2}^{2}}{E_{2}} \\
P_{\max }=\frac{1}{\pi} \sqrt[3]{6 \frac{P}{r_{1}^{2} k^{2}}}
\end{gathered}
$$

for CoCrMo

$$
\begin{aligned}
& E_{1}=2,1 * 10^{5} \mathrm{MPa} \\
& v_{1}=0,3
\end{aligned}
$$

for UHMWPE

$$
\begin{aligned}
& E_{2}=1000 \mathrm{MPa} \\
& v_{1}=0,4
\end{aligned}
$$

\section{Physical model of the pair "sled - flat insert"}

The accepted physical model for calculation of the pair "sled - flat insert" was assumed to reflect all geometrical, material features and load conditions of the real one. The accepted simplifications should make it possible to conduct the numerical simulation process and obtain objective and reliable results. 
The numerical analysis of contact phenomena taking place in artificial joints makes us aware of the wear-off process of the insert made of UHMWPE polyethylene commonly used in knee joint endoprostheses.

Creating the numerical models of bones with all necessary components is possible only when some geometrical simplifications are used. When analyzing contact strength and stress arising in polyethylene inserts, it is enough to build up a simplified model consisting of metal sled and polyethylene insert, only to settle the values and analyze phenomena occurring in the friction pair of endoprosthesis.

\section{The geometrical model of sled and flat insert}

The model presented in the following paper consists of elements being parts of endoprosthesis: femoral, tibia and binding polyethylene insert, which can optionally be equipped with a stabile metal base [1-3].

The conducted research was to show what is the influence of the geometry of the collaborating kinematic pair of the implant on the stress pattern in the contact area between the sled - flat insert.

The tests were run using the ADINA system 7.5.1. based on the finite elements method. They were conducted on the model of sled endoprosthesis with specific parameters of slide surfaces of sleds and with polyethylene flat inserts of various thicknesses.

The range of the load used during simulations was corresponding with the real physiological loads and the PE insert was deformed in the resilient range. In the presented paper to UHMWPE polyethylene and the alloys CoCrMo and Ti6Al4V are isotropic with constant mechanical features.

Figure 1 presents the physical model of metal sled cooperating with PE flat insert. In these particular models the metal sleds are geometrically identical.

Figure 2 presents geometrical model of the pair sled - PE flat insert.

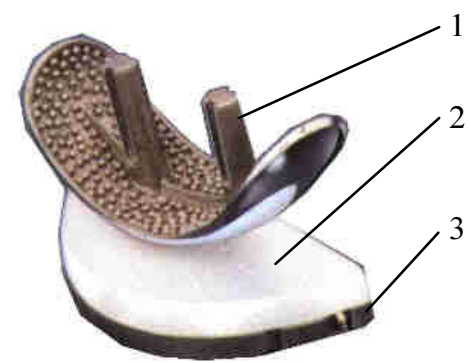

Fig. 1. Physical model of the pair sled - polyethylene flat insert. Sled endoprosthesis of knee joint by W. LINK, 1 - femoral element, 2 - polyethylene flat insert, 3 - tibia element

The accepted mesh for the calculations finite elements was built of 3600 cubic elements of 3D Solid type and 4312 nodes. The model had 12936 degrees of freedom. 


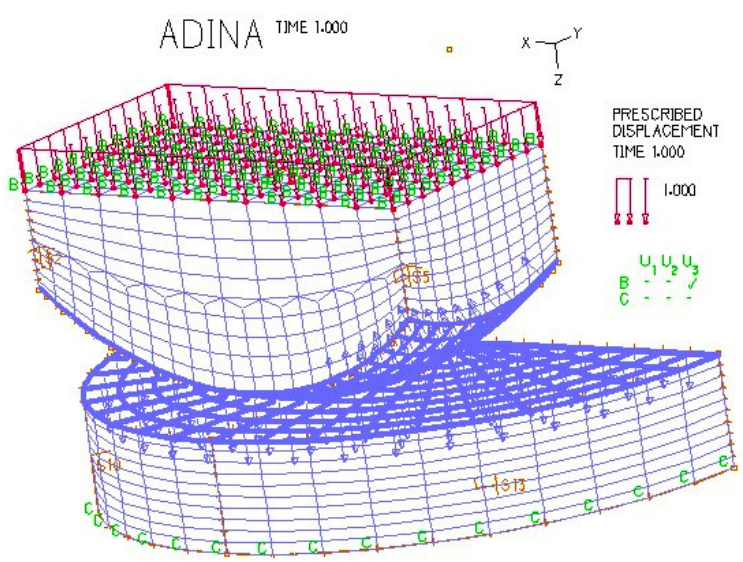

Fig. 2. Geometrical model of the pair sled - flat polyethylene insert. Finite elements mesh, load, degrees of freedom and contact area. General view

The main goal of the numerical analysis was to define the values of the stress that occur in UHMWPE polyethylene inserts and see how they are deformed by the pressing sled [4].

\section{Material data. The accepted model of the load}

The calculations were taken for flat inserts made of UHMWPE polyethylene of higher density.

The boundary conditions defined for the calculations are the mechanical values of the endoprosthesis' elements and the values of mechanical loads. It was assumed that all materials included in models (the medical alloy Ti6Al4V, the alloy CoCrMo, polyethylene UHMWPE), are of linear - resilient features and are homogeneous [5]. Also their mechanical values are constant. The values of features like the resilience module and Poisson's coefficient were chosen based on the trade literature.

The load put on the numerical models was caused by the influence that the femoral bone joint surfaces with the implanted endoprosthesis had on the polyethylene insert.

The above set is simplified because the tested strain and deformations are only for the weakest element which is the insert, but it is its strength that determined the durability of the implanted endoprosthesis.

\section{The analysis of strain and deformations in the set sled - flat insert in the sled endoprosthesis by W. LINK}

The tests results presented in the figures below show the values of the stress in cross-sections of the analyzed models mostly for particular types of polyethylene 
inserts. Figure 3 presents the reduced strain pattern occuring in the subsurface area of the insert. As far as the strength of the material is concerned, one of the very important things is the deformation degree of the material which the inserts are made of. The UHMWPE is the weakest point of the endoprosthesis, that's why it is important to present the reduced stress pattern and deformation degree in the contact area between the sled and the insert, what is shown in Figure 4.

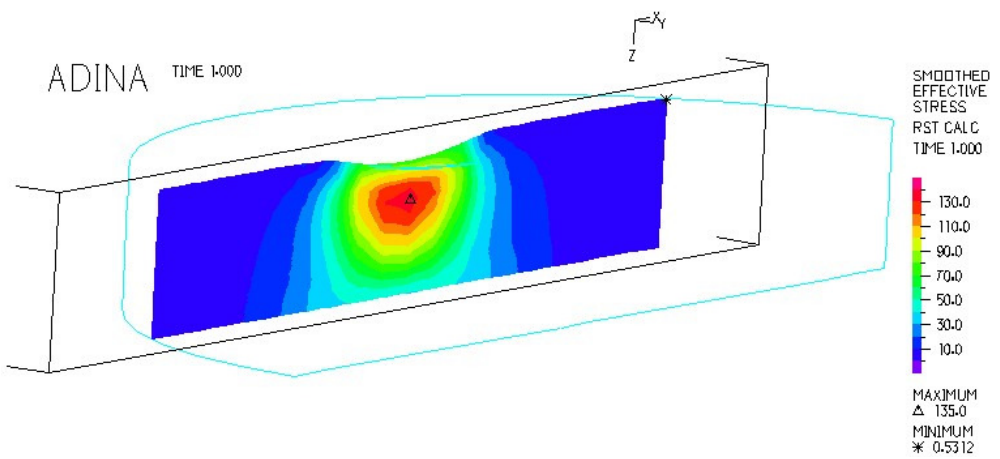

Fig. 3. Contact stress pattern in the flat polyethylene insert. General view of the model. Load $1500 \mathrm{~N}$

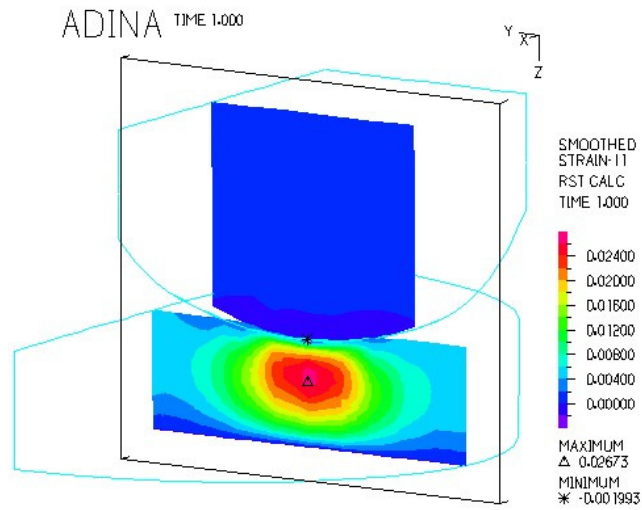

Fig. 4. Strain pattern of the material occuring under the surface of the flat polyethylene insert cooperating with metal sled. Along the section of the model. Load $1500 \mathrm{~N}$

The obtained numerical results are in accordance with Huber's theory (concerning the energy of deformation) which says that the value of the material's strength in any loaded point is this part of resilience energy, which is connected with formal deformation - only this kind of deformation can cause a critical state which leads to irreversible plastic deformations or cracks. The rest of resilience energy has no influence on strain as it does not affect the unity of the material.

The conducted tests clearly show that the stress is concentrated in the polyethylene insert right under the surface of the contact area between the two elements 
and the highest values are under the insert's surface. The features of max values of stress in the flat and spherical insert are significantly different. The tests proved the theory that the flat insert had higher strain values then the spherical one. The obtained results allow us to formulate the conclusions concerning the influence of some construction parameters of elements on stress values generated in polyethylene insert, which directly affects the durability of the endoprosthesis.

\section{Conclusions}

The conclusions drawn from the numerical simulations on knee joint endoprosthesis concerning the strain distribution in the implant:

1. The contact strain values can be decreased by proper adjustment of cooperating surfaces and substituting the linear contact by the surface one.

2. Specific set of friction pair sled - insert causes higher contact stress in the subsurface area. It is connected with the destructive material features causing delamination especially at the end of the process.

3. The conducted tests on stress pattern in sled - insert pair show that flat inserts generate higher stress than the spherical ones, regardless of their thickness.

4. The results present the contact areas and the fields of highest values of stress and displacement, and where the metal elements' prints in the polyethylene. It makes it possible to characterise particular endoprosthesis as far as the stress it generates is concerned, and furthermore - foresee how it will proceed later on.

\section{References}

[1] Będziński R., Biomechanika inżynierska, Oficyna Wydawnicza Politechniki Wrocławskiej, Wroclaw 1997.

[2] Gierzyńska-Dolna M., Biotribologia, Wydawnictwo Politechniki Częstochowskiej, Częstochowa 2002.

[3] Gierzyńska-Dolna M., Kubacki J., Wieczorek A., Tatar K., Mechanizm zużycia endoprotezy saneczkowej stawu kolanowego, Biology of Sport 1998, 112-119.

[4] Krzesiński G., Zagrajek T., Modelowanie własności mechanicznych kości, Biology of Sport $1998,15,8$.

[5] Marciniak J., Biomateriały, Wydawnictwo Politechniki Śląskiej, Gliwice 2002.

[6] Zakrzewski M., Zawadzki J., Wytrzymałość materiałów, Wrocław 1975.

[7] Zienkiewicz O.C., Metoda elementów skończonych, Wyd. Arkady 1972. 